Running head: EMOTIONAL ACCULTURATION

Manuscript in press at Personality and Social Psychology Bulletin

Where Do My Emotions Belong?

A Study of Immigrants' Emotional Acculturation

Jozefien De Leersnyder and Batja Mesquita

University of Leuven

Heejung S. Kim

University of California, Santa Barbara

Jozefien De Leersnyder (Jozefien.DeLeersnyder@psy.kuleuven.be) \& Batja Mesquita (Mesquita@psy.kuleuven.be), Center for Social and Cultural Psychology, University of Leuven; Heejung Kim (kim@ @sych.ucsb.edu), Department of Psychology, University of California, Santa Barbara.

This research was supported by a research fund of the University of Leuven to the second author.

Correspondence concerning this article should be addressed to Jozefien De Leersnyder, Center for Social and Cultural Psychology, Tiensestraat 102, bus 3727, 3000 Leuven, Belgium. Phone: +32 (0)16 325632 (work) or +32 (0)472 817398 (alternate). Fax: +32 (0)16 325923. E-mail: Jozefien.DeLeersnyder@psy.kuleuven.be 


\begin{abstract}
The emotional experiences of people who live together tend to be similar; this is true for dyads and groups, but also for cultures. It raises the question whether immigrants' emotions become more similar to host culture patterns of emotional experience; do emotions acculturate? Two studies, on Korean immigrants in the US (Study1) and on Turkish immigrants in Belgium (Study2), measured emotional experiences of immigrants and host group members with the Emotional Patterns Questionnaire. To obtain a measure of the immigrants' emotional similarity to the host group, their individual emotional patterns were correlated to the average pattern of the host group. Immigrants' exposure to and engagement in the host culture, but not their acculturation-attitudes, predicted emotional acculturation.
\end{abstract}

Keywords: Culture, emotion, acculturation, emotional similarity, implicit measure 
Running head: EMOTIONAL ACCULTURATION

\section{Where Do My Emotions Belong? A Study of Immigrants' Emotional Acculturation}

People who live together, interact or cooperate tend to become more emotionally similar over time: Roommates, romantic couples, teams, and group-members grow emotionally more alike (e.g. Anderson, Keltner, \& John, 2003; Totterdell, 2000). Thus, people's emotions become attuned to their enduring social relationships.

Similarly, people who engage in the same cultural contexts share patterns of emotions: The frequencies and intensities of their emotions converge. For instance, research has found that people living in a North American context report high frequencies of socially disengaging emotions (e.g., pride and anger), and relatively low rates of socially engaging emotions (e.g., sympathy and shame), while people living in a Japanese context report high frequencies of engaging and low rates of disengaging emotions (Kitayama, Mesquita \& Karasawa, 2006).

Whether a person experiences a specific emotion frequently or rarely, seems to be systematically related to their culture's core meanings and practices (Markus \& Kitayama, 1994; Mesquita \& Leu, 2007). For example, anger (an emotion by which a person claims power and control in a relationship) is readily experienced in cultural groups in which autonomy, independence, power and control are central (Tiedens, 2001); by contrast, anger is rarely experienced in cultures that value harmony and equality in relationships and that, therefore, consider anger an immature, dangerous, or merely inappropriate emotion (Briggs, 1970). These studies also imply that in addition to the frequency and intensity of experiencing specific emotions, the meaning and association of these emotions differ across cultures. That is, even the same emotion, such as anger, seems to be experienced differently across cultures. In a culture that emphasizes independence and personal control, anger would be experienced with a feeling of being in control but in a culture that emphasizes interdependence, anger would be experienced with a feeling of guilt. Similarly, high arousal emotions, such as excitement, may be experienced positively in a culture in which personal agency is valued, 
Running head: EMOTIONAL ACCULTURATION

but more negatively in a culture in which social harmony is valued (Tsai, Knutson, \& Fung, 2006).

Therefore, people embody cultural ideas in the form of emotions (Bruner, 1996): Their emotional patterns express and reinforce the prevalent meanings and practices in their cultural contexts and, therefore, implicitly signal their socio-cultural affiliations. People's fit with the modal emotional pattern of the culture in which they engage, may thus reflect their levels of sharing and participation in the culture's meanings and practices. We expect that emotional fit may facilitate a person's navigation in his/her social world, and thus will benefit that person's wellbeing. This is consistent with the findings that emotionally similar teams and groups tend to be closer, happier and more identified than more divergent groups (Smith, Seger, \& Mackie, 2007; Totterdell, Kellett, Briner, \& Teuchmann, 1998), and that emotional similarity in married or dating couples is associated with relationship satisfaction (e.g. Anderson et al., 2003). It is also supported by the finding in the research described earlier (Kitayama, Mesquita, \& Karasawa, 2006) that Japanese respondents who reported more socially engaging, and American respondents who reported more socially disengaging emotions, tended to be happy. Emotional concordance may thus be a measure of (social) adjustment.

The central question of this research is to what extent emotions acculturate: To what degree and under which circumstances do immigrants' emotional patterns become more similar to the emotional patterns of the majority group of their country? Based on the research that shows that emotional experiences grow more alike among couples, teams, and group members (e.g. Anderson et al., 2003; Totterdell, 2000), we expect that people's emotional patterns change in response to their engagement in a (new) cultural context. While there is a large body of research on acculturation (e.g., Berry, Phinney, Sam, \& Vedder, 2006; Ward, Bochner, \& Furnham, 2001; Ryder, Alden \& Paulhus, 2000), most of it has been concerned with socio-cultural and health outcomes and the particular acculturation strategies associated 
Running head: EMOTIONAL ACCULTURATION

with them (Berry \& Kim, 1988; Myers \& Rodriguez, 2002). To date, there has been little focus on the acculturation of core psychological processes themselves, such as cognition, motivation and emotion (for an exception on the acculturation of self-esteem, see Heine $\&$ Lehman, 2004). The current research is on emotional acculturation which, just like other types of psychological acculturation, may consist of "psychological changes and eventual outcomes" that result from a person's encounters with another culture (Berry \& Sam, 1997, p. 293). Emotional acculturation thus refers to changes in emotional patterns due to an immigrant's exposure to and contact with a new or second cultural context.

We adopt a cultural psychology perspective on acculturation in which psychological processes are seen as mutually constitutve with cultural meanings and practices (Fiske, Kitayama, Markus, \& Nisbett, 1998; Markus \& Kitayama, 2004; Shweder \& Sullivan, 1993). In this view, contact with a new culture may lead to changes in all aspects of people's psyches: People's psychological processes themselves, and their emotional experiences in particular, may thus be a function of acculturation. Since emotions imply socio-cultural affiliation, the fit or similarity between an immigrant's emotional pattern and the one typical of the host culture reflects that immigrant's internalization of the new culture; we refer to this fit as emotional concordance.

We aimed to measure emotional acculturation in an implicit manner. Rather than asking for a self-report of perceived emotional concordance, we measure the actual concordance between immigrants' emotional patterns and the average emotional pattern of a host culture sample. Thus, while we hypothesize that immigrants who engage in the meanings and practices of the new culture internalize this new culture, immigrants are less likely to be aware of this change. Therefore, emotional acculturation may not be accompanied by changes in the attitudes towards, or in the identification with the new culture. "Self-categorization [as a member of the heritage culture] persists long after the individual has made the necessary 
Running head: EMOTIONAL ACCULTURATION

cultural adaptations for effective living" (Hutnik, 1991, p. 159); conversely, immigrants who claim to be a member of the new (and desired) host group may not have internalized the host culture's meanings and emotions. It is possible, for instance, that a second generation Turkish immigrant in Belgium strongly identifies as a member of Turkish culture, while her emotional experiences have come to reflect more closely those of fellow Belgians. Thus, our implicit measure of emotional acculturation captures a process of acculturation that is related yet distinctive from more explicit measures of acculturation.

In order to investigate the phenomenon of emotional acculturation we measured immigrants' emotional concordance to the host culture. We examined to what extent this emotional concordance could be predicted by immigrants' exposure to and engagement in the host culture. ${ }^{1}$ A first study focused on Korean immigrants in the United States; a second study focused on Turkish immigrants and bi-culturals in Belgium. To measure emotional concordance, we developed the Emotional Patterns Questionnaire (EPQ) that prompts immigrants to describe their emotional experience, and then compares the patterns of answers with that of an average mainstream sample. The EPQ is an implicit measure of acculturation to the host culture because respondents rate their own emotions without being aware of the average mainstream pattern. The EPQ may, therefore, be less susceptible to selfpresentational biases than other acculturation scales, in which respondents are explicitly asked about their attitudes and preferences.

The main hypotheses were that immigrants' emotional concordance is associated with (a) their exposure to mainstream culture, and (b) their engagement in relationships with members of the host culture. Consistent with the literature on emotional similarity in dyads and teams, we expected that more time spent in the new culture, and a higher involvement with people from the mainstream culture both predict emotional concordance. Finally, we 
explored the relationship between our implicit measure of acculturation and explicit measures of adoption of the host culture. ${ }^{2}$

\section{Study 1}

In Study 1 we examined emotional acculturation in Korean immigrants in the US; European-Americans constituted the mainstream standard of comparison. Koreans were selected, because (a) East Asian and mainstream European-American emotional patterns have been shown to differ markedly (e.g, Kitayama, Markus \& Kurokawa, 2000), rendering any acculturative shifts visible, and (b) Koreans have demographics (education, employment) comparable to mainstream European-Americans (Terrazas, 2009), facilitating the comparison.

\section{Method}

\section{Participants}

Forty-seven Korean immigrants and 44 European-Americans who lived in Southern California communities, participated in the study. The samples did not differ in gender composition ( $46 \%$ female), or mean age $(M=37 ; S D=14)$. However, a higher proportion of Koreans (86\%) than European-Americans (60\%) were college-educated, $\chi^{2}=7.166, p=.007$. The majority of Korean participants $(72 \%)$ consisted of first generation immigrants who had lived in the US for an average of 21.41 years $(S D=16.39)$, which was about half of their lives (proportion of life spent in the US, $M=.54, S D=.34$ ).

\section{Materials and Procedure}

Emotional Patterns Questionnaire (EPQ). In order to measure emotional concordance we developed the EPQ. The EPQ prompts participants to describe a recently encountered situation that elicited one of four classes of emotions (positive engaged, positive disengaged, negative engaged, negative disengaged) that together constitute the domain of emotional experience both in North American and East Asian contexts (Kitayama et al., 2000; Kitayama et al., 2006). Moreover, the EPQ was administered for two relationship contexts: 
Running head: EMOTIONAL ACCULTURATION

Family and work/school. Participants first reported a situation from their recent past that matched the prompt (e.g., "a recent occasion at home or with your family in which you felt good about yourself" as a prompt for positive disengaged emotions in a family context). In each condition, participants then rated the reported experience on the same 20 emotion-items $(1=$ not at all $-7=$ extremely). These 20 items were chosen to represent a broad range of emotional experiences, and represented different positions on the valence, arousal and social engagement dimensions (Kitayama, Markus, \& Kurokawa, 2000; Russell \& Barrett, 1999). A content check confirmed that the situations described were consistent with the prompt. Moreover, a manipulation check confirmed that, in the large majority of cases, the reported emotions matched the one called for in the situation description. This was true for both cultural groups, see Table 1.

Emotional concordance with the host culture was calculated for each type of emotional situation $\mathrm{X}$ relationship context (e.g. positive disengaged in family context) separately. We first calculated the average host culture ratings for the 20 individual emotions; the so-called host culture's emotional pattern. We then correlated each person's emotional pattern (i.e. the ratings on each of the 20 emotions) to the average host culture's emotional pattern. This correlation is the person's emotional concordance score, i.e. the similarity between the person's emotional pattern and the mean pattern of the host group for a particular type of emotional situation in a particular relationship context (see Figure 1 for two examples of emotional concordance). To calculate the emotional concordance of European-American respondents, we corrected the average host culture's pattern by excluding the respondents' own scores. Because each participant completed two versions of the EPQ - one for each relationship context - we also calculated emotional concordance by respondent, by averaging each respondent's scores across the two social contexts. To test the hypotheses, we transformed the emotional concordance scores into Fisher Z-scores. 
Running head: EMOTIONAL ACCULTURATION

One of the sources of differences in emotional patterns may be that the emotion words included have different meanings across cultures. To check the structural equivalence of the 20 emotion items, we conducted a Simultaneous Component Analysis (Kiers, 1990). Three factors emerged reflecting (a) positive emotions (interested, strong, proud, close, respect, helpful); (b) negative engaged emotions (guilty, ashamed, afraid, indebt, worthless, embarrassed); and (c) negative disengaged emotions (upset, irritable, bored, ill feelings, resigned). The common factor-solution explained 59 and 51 percent of variance in the Korean and European-American samples respectively. Based on the factor solution, we recalculated emotional concordance, excluding three of the original 20 emotion items from further analyses (i.e., jealous, relying, surprised); these items loaded differently in the Korean and the European-American solution respectively, suggesting cross-cultural differences in their precise meaning.

The results will be reported based on this 17 -item measure of emotional concordance. Emotional concordance based on 20 items yielded largely the same results; any differences with the 17-item solution are reported in footnotes.

Acculturation measures. Our primary measure of exposure to North American culture was the proportion of life spent in host culture, which we calculated by dividing the number of years spent in the US by the actual age of the respondent. This measure was chosen because, in contrast to the number of years spent in the host culture, it is meaningful irrespective of the actual age of the immigrant. To increase comparability with other studies on acculturation, we will also report analyses that are based on the number of years spent in the host culture and the age of immigration.

A 4-item scale measured the degree of social contact with members of the host culture $(\alpha=.63)$. It consisted of one item on English language use -scale ranging from 1 (I speak Korean all the time) to 5 (I speak English all the time) - and 3 items on the ethnicity of 
Running head: EMOTIONAL ACCULTURATION

friends, colleagues and neighbours; scale from 1 (heritage culture only) to 5 (Euro-Americans only). Korean immigrants in the US had an average contact-level with Euro-Americans of $3.05(S D=.87)$ on a scale from 1-5.

Two scales measured attitudes towards adoption of mainstream values and customs (4 items, $\alpha=.69$ ) and attitudes towards social contacts with members of the host group (4 items, $\alpha=.83)$. The items for these explicit measures of acculturation were taken from the Vancouver Index of Acculturation (VIA; Ryder, Alden \& Paulhus, 2000) and were rated on scales from 1 (totally disagree) to 9 (totally agree). Attitudes towards adoption of mainstream values and customs consisted of the following four items: 1) I often participate in mainstream North American cultural traditions; 2) I often behave in ways that are 'typically' North American; 3) It is important for me to maintain or develop North American cultural practices; and 4) I believe in mainstream North American values. Attitudes towards social contacts with members of the host group included: 1) I would be willing to marry a North American person; 2) I enjoy social activities with typical North American people; 3) I am comfortable working with typical North American people; and 4) I am interested in having North American friends.

Although adoption of the mainstream culture is a single scale of the VIA, recent research has suggested that attitudes towards values and customs may be acquired at a different stage than attitudes towards contacts with the members of the cultural majority (Snauwaert, Soenens, Vanbeselaere, \& Boen, 2003). Therefore, we created two scales corresponding to these two aspects of acculturation.

Participants also completed a demographic questionnaire.

\section{Procedure}

Questionnaires were translated from English into Korean and back-translated into English by bilingual researchers. Research assistants recruited the participants in public places, such as malls, churches and coffee shops. Korean respondents were approached by bi- 
Running head: EMOTIONAL ACCULTURATION

cultural research assistants. Each participant received two EPQs that both pertained to the same type of emotion (e.g. positive disengaged), one for the work/school and one for the family context.

\section{Results and Discussion}

Group Difference in Emotional Concordance. Emotional concordance can only be meaningfully considered a measure of acculturation if it is higher for mainstream Americans than Koreans. We first checked if this condition was met. To consider the possibility that emotional concordance was, furthermore, moderated either by type of emotion or by relationship context, we conducted a Culture (European-American, Korean first generation, Korean later generation) X Valence (positive, negative) X Engagement (socially engaged, disengaged) repeated measures ANOVA with (Fisher-transformed) emotional concordance in each Relationship Context (school/work, family) as the repeated dependent variables.

The results yielded a main effect of culture, $\left(F(2,66)=5.139, p=.007, \eta^{2}=.139\right)$, which we further analysed using planned contrasts. European Americans $(M=.75, S D=.054$; mean $r=.64$ ) were in fact more emotionally concordant than first generation Korean immigrants $(M=.55, S D=.056$; mean $r=.50$; contrast estimate $=-.20, p=.015)$, but did not differ significantly from Korean-Americans who were born in the US $(M=.87, S D=.096$; mean $r=.70$; contrast estimate $=.12, p=.273$ ). This main effect was further qualified by the type of emotional situation, as indicated by a significant three-way-interaction between Culture, Valence and Engagement $\left(F(2,66)=4.022, p=.022, \eta^{2}=.109\right)$. Follow-up tests showed that first generation Koreans' emotional concordance scores were significantly lower than those of later generation Koreans and North-Americans in positive disengaged $(p<.05)$ and negative engaged emotional situations only $(\mathrm{p}<.05)$. Furthermore, across cultural groups, emotional concordance was higher in positive $(M=1.05, S D=.058$; mean $r=.78)$ than in negative $(M=.41, S D=.059$; mean $r=.39)$ situations $\left(F(1,66)=59.491, p \leq .001, \eta^{2}=\right.$ 
Running head: EMOTIONAL ACCULTURATION

.474). There were no differences in emotional concordance between Relationship Contexts; these contexts will be collapsed in the remainder of the results section.

Emotional Concordance and Contact with the Host Culture. In order to investigate the different predictors of emotional concordance (proportion of life spent in the US, number of years in the US (after controlling for age), age of immigration, and social contact with members of the mainstream culture) among Korean immigrants, we conducted four separate multiple hierarchical regression analyses. In each regression analysis, we controlled for Valence and Engagement as they were found to interact with the cultural differences in emotional concordance, and for (b) Educational attainment because the European-American and Korean samples differed with respect to education. In the last step of each analysis, we entered the interactions between the predictor of interest and Educational attainment and the predictor of interest and Valence (Table 2 panel A).

This study provided support for the notion of emotional acculturation: Korean immigrants' concordance with the mean US emotional pattern was associated with the proportion of life spent in the US (Analysis 1). The emotional concordance of a second (or later) generation immigrant (proportion of life spent in the US $=100 \%$ ) is .56 higher than that of a newly arrived immigrant (proportion of life spent in US $=0 \%$ ). Similarly, for each year the immigrant had spent in the US, his or her emotional concordance increased with .011 (Analysis 2). Furthermore, the younger the age of immigration, the higher the immigrants' emotional concordance with the host culture (Analysis 3). Also consistent with our hypothesis, the level of social contact with people from the mainstream culture was positively associated with the immigrant's emotional concordance (Analysis 4).

Emotional Concordance and Explicit Measures of Psychological Acculturation. To examine whether emotional concordance was related to explicit measures of acculturation, we conducted another regression analysis, again controlling for Valence and Engagement 
Running head: EMOTIONAL ACCULTURATION

(Analysis 5). Although there were no differences between mean levels on these explicit measures of acculturation (Attitudes towards the adoption of US values and customs: $M=$ 5.37, $S D=1.33$; attitudes towards social contacts with Euro-Americans: $M=5.37, S D=2.03$; $t(43)=.06, p=.953)$, positive attitudes towards contact with mainstream people significantly predicted emotional concordance, whereas attitudes towards the adoption of values and customs did not.

\section{Study 2}

Study 2 extended Study 1 to Turkish immigrant groups in Flanders, the Dutch language part of Belgium; Flemish Belgians served as the standard of comparison. We chose to focus on Turkish immigrant groups, because (a) there are marked differences between the emotional experiences of Turkish immigrants and those of mainstream people in the European contexts in which they live (Mesquita, 2001), and (b) the majority of Turkish immigrants in Belgium have relatively low status and educational attainment, which increased the contrast with Koreans in the US. Within the Turkish group, we sampled second generation immigrants in addition to first generation immigrants. Acculturation research typically includes second generation immigrants (e.g., Berry, Phinney, Sam, \& Vedder, 2006), because they live at the intersection of two cultures.

\section{Method}

\section{Participants}

Participants were 59 first and 85 second generation Turkish immigrants. A sample of 83 Flemish Belgians was matched to the Turkish groups on education (27\% college educated) and gender composition (54\% women). The mean age between the three samples differed $(F(2,222)=18.729, p \leq .001 ; M=34, S D=11.9$ for Turkish first generation; $M=26, S D=$ 6.6 for Turkish second generation, and $M=31, S D=8.8$ for Belgians). For the Turkish immigrants these age differences reflected the differences in actual age compositions between 
Running head: EMOTIONAL ACCULTURATION

first and second generation. The first generation immigrants had lived in Belgium for an average of 13 years $(S D=12.5)$, which resulted in an average proportion of life spent in Belgium of $.35(S D=.28)$.

\section{Materials and Procedure}

The EPQ. The EPQ used in Study 2 was identical to the one used in Study 1. Again, the manipulation check confirmed that the reported emotions were in line with the prompts, see Table 1, and this was true for each cultural group separately. As in Study 1, we computed emotional concordance scores based both on the cross-culturally similar emotion items and on all 20 emotion items. This time, the Simultaneous Component Analysis yielded four common factors that corresponded to the ones intended: Positive engaged (interested, close, respect, relying, helpful), positive disengaged (strong, proud, surprised), negative engaged (guilty, ashamed, indebted) and negative disengaged (upset, irritable, afraid, bored, ill feelings, worthless). This solution explained 53, 55 and 57 percent of variance in the Turkish first generation immigrant, Turkish second generation immigrant and Belgian sample respectively. Across cultural groups, seventeen emotions loaded similarly on the four factors; the other three (feeling resigned, jealous and embarrassed) were excluded from further analyses because these items had different loadings in the three separate solutions, suggesting crosscultural differences in their precise meaning.

Different from Study 1, respondents in this study reported two emotional instances that pertained to the same relational context and valence, but that differed with respect to the social engagement dimension. Accordingly, each person received two emotional concordance scores, one for the engaged, and one for the disengaged emotional situation. We also calculated each person's emotional concordance by averaging their scores across the types of engagement. 
Running head: EMOTIONAL ACCULTURATION

Similar to Study 1, we calculated the emotional concordance of Belgian respondents after correcting the average host culture's pattern for the respondents' own scores. Furthermore, all emotional concordance scores were transformed into Fisher's Z-scores before using them in further analysis.

Acculturation measures. As measures of exposure to Belgian culture, we included the proportion of life spent in host culture, the number of years spent in the host culture and the age of immigration.

The same scales as in Study 1 were used to measure attitudes towards adoption of mainstream values and customs (Cronbach's $\alpha=.75$ ), and attitudes towards social contacts with members of the host group (Cronbach's $\alpha=.63$ ).

The social contacts with members of the host culture scale (Cronbach's $\alpha=.76$ ) differed from the one used in Study 1, and consisted of seven items on the language used in different social contexts (e.g. with colleagues, neighbours, friends, siblings, children (if they had children), in the street, in shops). Respondents chose from three answer alternatives: $1=$ only Turkish, 2 = both Turkish and Dutch and $3=$ only Dutch. Since (a) Belgians do not have any knowledge of Turkish language, (b) Turkish immigrants share no other common language with Belgian people, and (c) Turkish is the language spoken amongst Turkish immigrants, this scale is an indirect measure of the degree to which one's social relationships are embedded in mainstream cultural contexts. On average, the level of contact of Turkish immigrants was $2.00(S D=.046)$

\section{Procedure}

The questionnaires used in Study 1 were translated from English into both Dutch and Turkish by bilingual researchers and then back-translated. Belgian respondents were recruited at a community college, which made it likely that they matched the Turkish respondents in terms of their socio-economic level. A small part of the Turkish immigrants (20\%) came from 
Running head: EMOTIONAL ACCULTURATION

the same community college; the remaining Turkish participants responded to bilingual flyers they received in their mailboxes, in which they were invited to join one of the research meetings held at a community center in their (multi-ethnic) neighborhood. A research team consisting of mainstream Belgian and bi-cultural Turkish research assistants explained and administered the questionnaires. As in Study 1, respondents received a package including two different versions of the EPQ together with demographic and acculturation questionnaires.

\section{Results and Discussion}

Group Difference in Emotional Concordance. To allow for the possibility that cultural differences in emotional concordance were moderated by social context or type of emotion, we conducted a Culture (Turkish first generation, Turkish second generation, Belgian) X Valence (positive, negative) X Relationship Context (work/school, family) repeated measures ANOVA with two levels of (Fisher-transformed) emotional concordance (engaged, disengaged situations) as the repeated dependent variables. Similarly to Study 1, there were cultural differences in emotional concordance, although the effect was only marginally significant, $\left(F(2,199)=2.772, p=.065, \eta^{2}=.027\right)$. Planned contrasts revealed, however, that emotional concordance was significantly higher for Belgians $(M=.72, S D=$ .040 ; mean $r=.61)$ than for Turkish first generation immigrants $(M=.59, S D=.045$; mean $r$ $=.53$; contrast estimate $=-.132, p=.029)$. Emotional concordance of Turkish respondents who were born in Belgium $(M=.65, S D=.037$; mean $r=.57)$ only marginally differed from the mean emotional concordance for Belgians (contrast estimate $=-.099, p=.072$ ). Furthermore, there was a main effect of Valence $\left(F(1,199)=235.716, p \leq .001, \eta^{2}=.542\right)$ showing that emotional concordance was higher in positive $(M=.97, S D=.034$; mean $r=$ $.75)$ than in negative $(M=.33, S D=.033$; mean $r=.32)$ situations. This main effect of Valence was further qualified by a significant interaction of the within-subject variable of engagement and valence (Pillai's Trace $\left.=.034, F(1,199)=7.033, p=.009, \eta^{2}=.034\right)$ 
Running head: EMOTIONAL ACCULTURATION

indicating that in positive situations emotional concordance was higher for engaged situations whereas in negative situations emotional concordance was higher for disengaged situations. Relationship Context did not affect the level of emotional concordance.

Emotional Concordance and Contact with the Host Culture. To test the hypotheses, we followed the same data-analytic strategy as in Study 1. In all regression analyses pertaining to the Turkish immigrants, we controlled for Valence and Educational attainment, and added the interactions between the predictor of interest and Educational attainment and the predictor of interest and Valence in the last step of each regression analysis (Details of the analyses can be found in Table 2 panel B). Consistent with our hypothesis, the proportion of life an immigrant had spent in Belgium was associated with the immigrant's emotional concordance (Analysis 1). The number of years an immigrant had spent in Belgium, after controlling for his actual age, was a predictor of emotional concordance as well: For each year the immigrant had spent in Belgium, his or her emotional concordance increased with .013 (Analysis 2). Similar to the results of Study 1, the younger the age of immigration, the higher the immigrants' emotional concordance (Analysis 3$)^{3}$. Although the number of social relationships with Belgians did not significantly affect emotional concordance, we found a significant interaction with Valence (Analysis 4). Simple slopes analyses revealed that the number of social relationships with Belgians was positively associated with emotional concordance in negative emotional situations only (simple slope for negative situations $=.12, t(133)=1.409, p($ one tailed $)=.08$ and simple slope for positive situations $=-.10, t(133)=-1.268, p($ one tailed $)=.10)$.

\section{Emotional Concordance and Explicit Measures of Psychological Acculturation.}

The analyses of Study 1 were repeated here (Table 2, Panel B, Analysis 5). A paired t-test showed that Turkish immigrants in Belgium had more positive attitudes towards social contacts with Belgians $(M=4.88, S D=1.17)$ than towards the adoption of Belgian values and 
Running head: EMOTIONAL ACCULTURATION

customs $(M=4.11, S D=1.37 ; t(142)=-7.178, p \leq .001)$. However, in partial replication of Study 1, Study 2 did not yield a significant association between the attitudes towards adoption of values and traditions and emotional concordance, and neither there was an association between attitudes towards social contacts with Belgians and emotional concordance.

\section{Study 2A}

Study 2A was an extension aimed to test if the results from Study 2 would hold given a standard based on Belgian university students, rather than on a sample matching the immigrants. Since community samples tend to be characterized by large within-group variability, Study 2A aims to establish replicability of the results when the Belgian emotional patterns were derived from a relatively homogeneous student sample.

\section{Method}

\section{Participants}

One hundred eighty eight Belgian university students (Mean age: 20, $S D=1.9 ; 88 \%$ female) participated in the study as part of a course requirement.

\section{Materials and procedure}

The EPQ used in Study 2A was identical to the ones used in the first two studies. Due to time constraints, students were allocated to one of eight conditions (Valence X Engagement X Relationship context) in which they completed one version of the EPQ (e.g., 'a situation in which you felt bad about yourself at school'). The manipulation check confirmed that the students' reported emotions were in line with the prompts, see Table 1. The Simultaneous Component Analysis on the emotion items yielded four common factors, and explained 53, 55 and $62 \%$ of the variance in the Turkish first generation, Turkish second generation and Belgian student sample respectively. The same 3 emotions as in Study 2 (i.e. jealous, resigned, embarrassed) emerged as cross-culturally different in meaning (i.e., in different cultural contexts they loaded on different factors). Therefore, emotional patterns in Study 2A 
Running head: EMOTIONAL ACCULTURATION

were computed on the basis of the 17 cross-culturally equivalent emotions, as they were in Study 2. Participants' emotional concordance was computed in the same way as in Study 2; the only difference was that the reference point was the average student emotional patterns. While students ended up with only one emotional concordance score per person (they reported only one emotional situation), each immigrant ended up with two since they had completed two versions of the EPQ. To test our hypothesis, we calculated an emotional concordance score per respondent. For the Turkish immigrants this meant that we averaged across disengaged and engaged emotional situations. Hypotheses were tested based on Fishertransformed concordance scores. Other acculturation measures, such as those on attitudes or social contact, were similar to the ones used in Study 2.

\section{Results and Discussion}

Group Difference in Emotional Concordance. An ANOVA with the emotional concordance score as dependent variable and Culture, Valence and Context as predictors, explained 54\% of the variance in emotional concordance scores. There was a significant main effect of Culture, $\left.F(2,330)=22.550, p \leq .001, \eta^{2}=.120\right)$; subsequent analyses yielded that both the first generation $(M=.54, S D=.047$; mean $r=.49)$ and the second generation $(M=$ $.62, S D=.043$; mean $r=.55$ ) immigrant groups showed lower emotional concordance scores than Belgian students $(M=.87, S D=.029$; mean $r=.70)$. Similar to both studies 1 and 2 , there was a highly significant main effect of Valence $\left(F(1,330)=45.484, \mathrm{p} \leq .001, \eta^{2}=\right.$ $.471)$, showing that, across cultural groups, emotional concordance was higher in positive ( $M$ $=1.08, S D=.032 ;$ mean $r=.79)$ than in negative $(M=.27, S D=.034 ;$ mean $r=.27)$ situations. A main effect of context $\left(F(1,330)=4.499, p=.035, \eta^{2}=.013\right)$, revealed that emotional concordance was higher for work/school contexts $(M=.73, S D=.034$; mean $r=$ .62 , ) than for family contexts $(M=.63, S D=.033$; mean $r=.55)$. However, pairwise comparisons revealed that this difference was significant for Belgian students only (mean 
difference $=.085, F(1,330)=.798, p=.372$ for Turkish first generation immigrants; mean difference $=.074, F(1,330)=.745, p=.389$ for Turkish second generation immigrants; and mean difference $=.139, F(1,330)=5.779, p=.017$ for Belgian students $)$, which may have to do with the fact that these respondents were all classmates.

Emotional Concordance and Contact with the Host Culture. Contact with the host culture predicted emotional concordance, irrespective of whether the measure for emotional concordance was based on the Belgian students' emotional patterns, or on the emotional patterns of the community samples. The only difference yielded by the two measures of concordance pertained to the age of immigration, which predicted emotional concordance when it was based on similarities with the community sample, but not with the student sample. Details of these analyses can be found in Table 2, panel B, Study 2A. Similarly to Study 2 with the Belgian community emotional patterns as the standards, we found in Study 2A that the interaction of social relationships with valence was significant. Consistent with Study 2, simple slopes analyses subsequently revealed that the number of social relationships with Belgians was positively associated with emotional concordance in negative emotional situations only ( simple slope for negative situations $=.20, t(132)=2.25, p($ one tailed $)=.013$ and simple slope for positive situations $=-.07, t(132)=-.85, p($ one tailed $)=.20)$.

\section{Emotional Concordance and Explicit Measures of Psychological Acculturation.}

Consistent with Study 2, emotional concordance was neither predicted by immigrants' attitudes towards the adoption of mainstream values and customs nor by the level of social contact with members of the mainstream.

\section{General Discussion}

Emotional Acculturation. Two studies suggested the existence of emotional acculturation; that is, emotional concordance appeared to be higher for those immigrants who spent more time in the new culture or who engaged more in relationships with host group 
Running head: EMOTIONAL ACCULTURATION

members. Thus, emotional concordance could be predicted by the immigrant's exposure to the host culture. Emotional acculturation regards the patterns of emotions, rather than the mean levels of intensity. Exposure to the mainstream culture neither predicted immigrants' mean score on the emotion scales nor did it predict mean levels of individual emotions. ${ }^{4}$

Differences in emotional patterns emerged against the backdrop of comparable emotional situations. The matching of situations was accomplished by asking participants to describe an event from their own daily life that met the description of an emotional situation in a particular prompt (e.g., "some situations at your school or work make you feel good about your relationships with others”). Prompts were standardized with respect to a small number of situational dimensions that in the literature have been used to classify emotional situations: Valence (e.g., Russell \& Barrett, 1999; Watson \& Tellegen, 1999), engagement (Kitayama, Markus, \& Karasawa, 2000) and relationship context (Oishi, Diener, Scollon, \& BiswasDiener, 2004). Since the manipulation checks confirmed that the reported emotions were matching the situational prompts as expected (see Table 1), we have some preliminary evidence that the reported emotional events neither differ across cultural groups nor across acculturation levels, at least they did not differ on these three most important dimensions of emotional situations. Yet, patterns of emotional experiences differed in ways that may be considered evidence for emotional acculturation.

The findings of emotional acculturation were replicated across two contexts (U.S., Europe), and with two different immigrant groups (Korean, Turkish). Moreover, evidence for emotional acculturation was found for the Turkish immigrants, regardless of whether the Belgian standard of comparison consisted of emotional patterns reported by a community sample or of a sample of college students.

Positive vs. Negative Emotional Situations. Across cultural contexts, emotional concordance was higher for the positive than for the negative situations. This may be related 
Running head: EMOTIONAL ACCULTURATION

to the finding that different emotions co-vary more in positive than in negative situations. Both in Study 1 and in Study 2 the sum of variances of all individual emotions was higher in the negative (73.6 in Study 1 and 79.7 in Study 2) than in the positive situations (51.6 in Study 1 and 49.2 in Study 2), suggesting that the patterning of emotions in positive situations is relatively simple compared to the patterning of the same emotions in negative situations. It may be easier, then, to learn, and adapt to, the new culture's emotional pattern in positive than in negative emotional situations.

Emotional concordance might thus be higher for positive than for negative situations because negative situations are more complex. Developmental research corroborates this idea: It takes children longer to master emotion knowledge in the negative than in the positive domain. Whereas the knowledge of negative emotion words and antecedents was greater for children in secondary than in primary school, no differences were measured for positive emotion knowledge; primary school children have mastered all there is to know about positive emotion words and antecedents by the time they are in elementary school (Doost, Moradi, Taghavi, Yule, \& Dalgeish, 1999).

Although the concordance for positive and negative emotional situations differs, there is no indication that the process of emotional acculturation is different: An immigrant's emotional concordance is predicted by his or her exposure to mainstream culture, even after controlling for the valence of the emotion. Generally, the interactions with valence did not predict immigrants' emotional concordance. This justifies the conclusion that, for positive and negative emotions alike, individual differences in emotional concordance are predicted from exposure to the host culture. There is only one exception: For Turkish immigrants, emotional concordance in negative, but not in positive, situations was predicted by social contact with Belgians. Why emotional concordance in Turkish immigrants is facilitated by repeated interactions in negative situations only remains a question. 
Running head: EMOTIONAL ACCULTURATION

The Role of Culture in Emotions. The current studies also speak to the role of culture in emotions. First, the finding that the proportion of life an immigrant has spent in the host culture predicts emotional concordance suggests that a person's life experiences continue to shape their emotions beyond the first years of socialization. And while it is true that immigration at a younger age increases the chances of emotional concordance to the host culture, this may be true in part because the experience with the heritage culture is, by definition, limited at that point. Similarly, as the number of years an immigrant has spent in the host culture increases, so increases his or her concordance to the host culture's emotional patterns. The results of the current studies do not favor one particular conceptualization of exposure to the host culture above the other two, since the proportion of life spent in the US explained more variance in Korean's emotional concordance than the age of immigration and number of years spent in the host culture, respectively (Study 1), whereas the number of years in the host culture was a better predictor of Turkish immigrants' emotional concordance than the proportion of life spent in Belgium and the age of immigration respectively (Study 2).

Second, culture may find its way into people's emotional experiences through their intercultural - relationships and interactions. Just like spending time with roommates, partners, and team mates increases emotional convergence (Anderson et al., 2003; Totterdell, 2000), so does spending time with members of the host group predict the immigrants' emotional concordance. While the processes underlying emotional convergence have not been studied, the developmental emotion literature (e.g., Saarni, 1997) suggest that "our embeddedness in relationships with others provides the diversity of emotional experience, the challenges of emotional coping, and the immensely rich ways in which we communicate our emotional experiences to others" (p. 38), and, therefore, that emotional patterns may be 'negotiated' in these interpersonal relationships. The idea is that interactions with others may 
produce successive (not end-point oriented) changes in emotions (Saarni, 2008) that enhance functionality to the particular social context.

Interpersonal relationships do not take place in a vacuum, but are rather culturally contextualized. As the emotions that prevail and are normative differ across cultural contexts, so may the emotions modeled and encouraged in the interactions within different contexts (Mesquita, 2010). For immigrants this means that each interaction that takes place in the new cultural context will model and reward emotional patterns that are different from those prevalent and valued in their culture of origin. Each interaction may thus produce successive changes in emotions that incrementally transform the immigrants' patterns of emotional responding. Naturally, based on the data we cannot claim any knowledge about the direction of the relationship between emotional acculturation and the interactions with host culture members.

What Changes Underlie Emotional Acculturation? Future research is needed to shed light on the underlying processes of emotional acculturation. Which are the changes that underlie the resulting shifts in emotional patterns? We can conceive of two different paths to emotional acculturation that are not mutually exclusive. Emotional patterns may change either because immigrants who are introduced in the new culture will experience different situations, or because immigrants start appraising the same situations differently. Whereas the first mechanism focuses on the external component of acculturation (i.e., changing surroundings), the second mechanism focuses on the internal component of acculturation (i.e., changing psychological processes).

Consistent with the idea that emotional acculturation is related to changes in the external world, is the finding in other research that different cultural contexts are characterized by specific 'tasks' (Kitayama \& Imada, 2010). For example, the ideal general goal state of 'independence' that is encouraged and promoted by most North American 
Running head: EMOTIONAL ACCULTURATION

cultural contexts (e.g. Markus \& Kitayama, 1994), can be achieved by performing various tasks, such as expressing one's unique self (Kim \& Markus, 1999), performing personal goal pursuit and self-promotion (Oishi \& Diener, 2001), and maintaining high self-esteem (Crocker \& Park, 2004).

Emotional acculturation may reflect an immigrant's level of engagement in the tasks of the host culture. If this explanation of emotional concordance was right, we would expect that the situations reported by immigrants whose patterns of emotions are least concordant with the mainstream culture, differ more from the emotional situations reported by mainstream respondents than situations reported by emotionally concordant immigrants. Unfortunately, the situational descriptions collected in the studies reported did not allow us to compare the emotional situations in detail.

Alternatively, emotional acculturation may consist of changes in psychological processes, particularly in the ways the same situations are appraised. As appraisals constitute the emotional experience (Barrett, Mesquita, Ochsner \& Gross, 2007), and appraisal tendencies differ across cultures (Mesquita \& Albert, 2007; Scherer, 2009), changes in these tendencies may result in the shifts in experience seen in emotional acculturation.

Implicit vs. Explicit Acculturation. Emotional concordance was unrelated to immigrants' attitudes towards (a) the adoption of values and traditions (Study 1 and 2) and (b) social relationships with members of the mainstream (Study 2). This suggests that emotional acculturation (i.e. acculturation of an implicit psychological tendency) is unrelated to the attitudes towards acculturation (i.e., explicit beliefs). Thus, it is possible to welcome a new culture without being emotionally concordant to it (e.g., new immigrants), or conversely, to be reluctant to adopt mainstream culture's values, and yet to be emotionally concordant (e.g., second generation). This finding echoes the recent suggestion of Kitayama and Imada (2010) that "explicit beliefs may be quite independent of implicit psychological tendencies" (p.186). 
Running head: EMOTIONAL ACCULTURATION

This finding has major implications for research on acculturation. It suggests that acculturation is no monolithic concept (cf., Phinney \& Flores, 2002), and that different facets of psychological functioning may acculturate in different directions or at different rates. It is possible that explicit measures of acculturation - measuring attitudes or beliefs - represent the immigrant's desire to be part of mainstream culture, whereas implicit measures - such as our measure of emotional concordance to the host-culture - reflect the degree to which an immigrant's psychology is actually contingent on the social and reinforcement structures of host culture. 


\section{References}

Anderson, C., Keltner, D., \& John, O. P. (2003). Emotional convergence between people over time. Journal of Personality and Social Psychology, 84, 1054-1068.

Barrett, L. F., Mesquita, B., Ochsner, K. N., \& Gross, J. J. (2007). The experience of emotion. Annual Review of Psychology, 58, 373-403.

Berry, J. W., \& Kim, U. (1988). Acculturation and mental health. In P. R. Dasen, J. W. Berry \& N. Sartorius (Eds.), Health and cross-cultural psychology: Towards applications (pp. 207-238). Newbury Park, CA: Sage Pubilcations.

Berry, J. W., Phinney, J. S., Sam, D. L., \& Vedder, P. (2006). Immigrant youth in cultural transition. Acculturation, identity, and adaptation across national contexts. Mahwah, J: Lawrence Erlbaum Associates.

Berry, J. W., \& Sam, D. L. (1997). Acculturation and adaptation. In J. W. Berry, M. H. Segall \& C. Kagitcibasi (Eds.), Handbook of cross-cultural psychology $\left(2^{\text {nd }}\right.$ ed., Vol. 3, pp. 291-326). Needham Heights, MA: Allyn and Bacon.

Briggs, J. L. (1970). Never in anger: Portrait of an Eskimo family. Cambridge, MA: Harvard University Press.

Bruner, J. (1996). Frames for thinking: Ways of making meaning. In D. Olsen \& N. Torrance (Eds.), Modes of thought: Explorations in culture and cognition. (Vol. 8, pp. 93-105). New York, NY: Cambridge University Press.

Crocker, J., \& Park, L. E. (2004). The costly pursuit of self-esteem. Psychological Bulletin, $130,392-414$

Doost, H. T. N., Moradi, A. R., Taghavi, M. R., Yule, W., \& Dalgeish, T. (1999). The development of a corpus of emotional words produced by children and adolescents. Personality and Individual Differences, 16, 322-340.

Fiske, A. P., Kitayama, S., Markus, H. R., \& Nisbett, R. E. (1998). The cultural matrix of 
social psychology. In D. T. Gilbert \& S. T. Fiske (Eds.), The handbook of social psychology, (4 ${ }^{\text {th }}$ ed., Vol. 2, pp. 915-981). New York, NY: McGraw-Hill.

Heine, S., \& Lehman, D. (2004). Move the body, change the self: Acculturative effects of the self-concept. In M. Schaller, Crandall, C. (Ed.), The psychological foundations of culture (Vol. 8, pp. 305-332). Mahwah, NJ: Lawrence Erlbaum.

Hutnik, N. (1991). Ethnic minority identity: A social psychological perspective. Oxford, UK: Clarendon.

Kiers, H.A.L. (1990), A program for simultaneous component analysis. IEC-programma, Groningen.

Kim, H., \& Markus, H. R. (1999). Deviance or uniqueness, harmony or conformity: A cultural analysis. Journal of Personality and Social Psychology,77, 785-800.

Kitayama, S., \& Imada, T. (2010). Implicit independence and interdependence: A cultural task analysis. In Mesquita, B., Barrett, L. F., Smith, E.R. (Eds.). The Mind in Context (pp. 174-200). New York, NY: Guilford.

Kitayama, S., Markus, H.R., \& Kurokawa, M. (2000). Culture, emotion, and well-being: Good feelings in Japan and the United States. Cognition and Emotion, 14, 93-124.

Kitayama, S., Mesquita, B., \& Karasawa, M. (2006). The emotional basis of independent and interdependent selves: Socially disengaging and engaging emotions in the US and Japan. Journal of Personality and Social Psychology, 91(5), 890-903.

Markus, H. R., \& Kitayama, S. (1994). The cultural construction of self and emotion: Implications for social behavior. In S. Kitayama \& H. R. Markus (Eds.), Emotion and culture: Empirical studies of mutual influence (pp. 89-130). Washington, DC: American Psychological Association.

Markus, H. R., \& Kitayama, S. (2004). Models of agency: Sociocultural diversity in the construction of action. In G. Berman \& J. Berman (Eds.), Nebraska Symposium on 
Running head: EMOTIONAL ACCULTURATION

Motivation: Vol. 49. Cross-cultural differences in perspectives on the self (pp. 1-57). Lincoln NE: University of Nebraska Press.

Mesquita, B. (2001). Emotions in collectivist and individualist contexts. Journal of Personality and Social Psychology, 80(1), 68-74.

Mesquita, B. (2010). Emoting: A contextualized process. In Mesquita, B., Barrett, L. F., Smith, E.R. (Eds.). The Mind in Context (pp.83-104). New York, NY: Guilford.

Mesquita, B., \& Albert, D. (2007). The cultural regulation of emotions. In J. J. Gross (Ed.), The handbook of emotion regulation (pp. 486-503). New York, NY: Guilford.

Mesquita, B., \& Leu, J. (2007) The cultural psychology of emotions. In S. Kitayama \& D. Cohen (Eds.), Handbook for cultural psychology (pp. 734-759). New York, NY: Guilford.

Myers, H. F., \& Rodriguez, N. (2002). Acculturation and physical health in racial and ethnic minorities. In K. M. Chun, P. Balls Organista, \& G. Marin (Eds.), Acculturation: Advances in theory, measurement, and applied research (pp. 163-185). Washington, DC: American Psychological Association.

Oishi, S., \& Diener, E. (2001). Goals, culture, and subjective well-being. Personality and Social Psychology Bulletin, 27, 1674-1682.

Oishi, S., Diener, E., Scollon, C. N., \& Biswas-Diener, R. (2004). Cross-situational consistency of affective experiences across cultures. Journal of Personality and Social Psychology, 86, 460-472.

Phinney, J.S., \& Flores, J. (2002). "Unpackaging" acculturation: Aspects of acculturation as predictors of traditional sex role attitudes. Journal of Cross-Cultural Psychology, 33 (3), 320-331.

Russell, J.A., \& Barrett, L.F. (1999). Core affect, prototypical emotional episodes, and other 
Running head: EMOTIONAL ACCULTURATION

things called emotion: Dissecting the elephant. Journal of Personality and Social Psychology, 76(5), 805-819.

Ryder, A., Alden, L., \& Paulhus, D. (2000). Is acculturation unidimensional or bidimensional? A head-to-head comparison in the prediction of personality, selfidentity, and adjustment. Journal of Personality and Social Psychology, 79, 49-65.

Saarni, C. (1997). Emotional competence and self-regulation in childhood. In P. Salovey\&D. J. Sluyer (Eds.), Emotional development and emotional intelligence: Educational implications (pp. 35-66). New York, NY: Basic Books.

Saarni, C. (2008). The interface of emotional development with social context. In M. Lewis, J.M. Haviland-Jones \& L.F. Barrett Handbook of Emotions (pp. 332-347). New York, NY: Guilford.

Scherer, K. R. (2009). The dynamic architecture of emotion: Evidence for the component process model. Cognition \& Emotion, 23(7), 1307-1351.

Shweder, R., \& Sullivan, M.A. (1993). Cultural Psychology: Who needs it? Annual review of Psychology, 44, 497-523.

Smith, E. R., Seger, C. R., \& Mackie, D. M. (2007). Can emotions be truly group level? Evidence regarding four conceptual criteria. Journal of Personality and Social Psychology, 93(3), 431- 446.

Snauwaert, B., Soenens, B., Vanbeselare, N., \& Boen, F. (2003). When integration does not necessarily imply integration. Different conceptualizations of acculturation orientations lead to different classifications. Journal of Cross-Cultural Psychology, 34 (2), 231-239.

Terrazas, A. (2009). Korean Immigrants in the United States. Retrieved from http://www.migrationinformation.org/USfocus/display.cfm?ID=716 
Running head: EMOTIONAL ACCULTURATION

Tiedens, L. (2001). Anger and advancement versus sadness and subjugation: the effect of negative emotion expressions on social status conferral. Journal of Personality and Social Psychology, 80, 86-94.

Totterdell, P. (2000). Catching moods and hitting runs. Journal of Applied Psychology, 85, 848-859.

Totterdell, P. Kellett, S., Briner, R.B. \& Teuchmann, K. (1998). Evidence of Mood Linkage in Work Groups. Journal of Personality and Social Psychology 74 (6), 1504-1515

Tsai, J. L., Knutson, B., \& Fung, H. H. (2006). Cultural Variation in Affect Valuation. Journal of Personality and Social Psychology 90 (2), 288-307.

Ward, C., Bochner, S., \& Furnham, A. (2001). The psychology of culture shock (2nd ed.). New York: Routledge.

Watson, D. \& Tellegen, A. (1999). Issues in the dimensional structure of affect-Effects of descriptors, measurement error, and response formats: Comment on Russell and Carroll (1999). Psychological Bulletin, 125, 601-610 
Running head: EMOTIONAL ACCULTURATION

Table 1 Manipulation Check: Mean Emotions across Different Types of Emotional Situations

\section{Emotion scale}

\begin{tabular}{|c|c|c|c|c|c|}
\hline & & $\begin{array}{c}\text { Positive } \\
\text { disengaged }\end{array}$ & $\begin{array}{l}\text { Positive } \\
\text { engaged }\end{array}$ & $\begin{array}{c}\text { Negative } \\
\text { disengaged }\end{array}$ & $\begin{array}{l}\text { Negative } \\
\text { engaged }\end{array}$ \\
\hline & Situational Prompt & Mean $(S D)$ & Mean $(S D)$ & Mean $(S D)$ & Mean $(S D)$ \\
\hline \multirow[t]{4}{*}{ Study 1} & Positive disengaged & $\mathbf{5 . 2 1}^{\text {abc }}(1.68)$ & $4.22^{\mathrm{a}}(1.35)$ & $1.94^{\mathrm{b}}(1.24)$ & $2.01^{\mathrm{c}}(1.94)$ \\
\hline & Positive engaged & $4.71(1.52)$ & $\mathbf{4 . 7 0}^{\mathrm{ab}}(1.17)$ & $2.13^{\mathrm{a}}(1.32)$ & $2.21^{\mathrm{b}}(1.16)$ \\
\hline & Negative disengaged & $3.11^{\mathrm{a}}(1.83)$ & $2.77^{\mathrm{b}}(1.35$ & $3.64^{\text {abc }}(1.32)$ & $2.80^{\mathrm{c}}(1.53)$ \\
\hline & Negative engaged & $3.14 \mathrm{c}(1.95)$ & $2.73 b(1.31)$ & $2.72(1.26)$ & $3.22(1.74)$ \\
\hline \multirow[t]{4}{*}{ Study 2} & Positive disengaged & $\mathbf{5 . 6 7}^{\text {abc }}(1.33)$ & $4.82^{\mathrm{a}}(1.30)$ & $1.92^{\mathrm{b}}(1.18)$ & $1.62^{\mathrm{c}}(.90)$ \\
\hline & Positive engaged & $5.35(1.60)$ & $\mathbf{5 . 2 3}^{\mathrm{ab}}(1.15)$ & $1.85^{\mathrm{a}}(1.12)$ & $1.74^{\mathrm{b}}(.99)$ \\
\hline & Negative disengaged & $3.02^{\mathrm{a}}(1.91)$ & $3.25^{\mathrm{b}}(1.52)$ & $\mathbf{4 . 2 3}^{\mathrm{abc}}(1.36)$ & $2.79^{\mathrm{c}}(1.82)$ \\
\hline & Negative engaged & $2.97(1.77)$ & $3.66(1.60)$ & $3.86(1.32)$ & $\mathbf{3 . 5 8}(1.87)$ \\
\hline \multirow[t]{4}{*}{ Study $2 A$} & Positive disengaged & $\mathbf{5 . 5 1}^{\text {abc }}(1.17)$ & $4.62^{\mathrm{a}}(1.34)$ & $1.51^{\mathrm{b}}(.71)$ & $1.66^{\mathrm{c}}(.74)$ \\
\hline & Positive engaged & $4.99^{\mathrm{a}}(1.28)$ & $\mathbf{5 . 5 0}^{\mathbf{a b c}}(1.02)$ & $1.69^{\mathrm{b}}(.95)$ & $2.12^{\mathrm{c}}(1.29)$ \\
\hline & Negative disengaged & $2.91^{\mathrm{a}}(1.31)$ & $2.80^{\mathrm{b}}(1.30)$ & $\mathbf{4 . 5 2}^{\mathrm{abc}}(1.05)$ & $3.56^{\mathrm{c}}(1.38)$ \\
\hline & Negative engaged & $2.93^{\mathrm{a}}(1.31)$ & $2.12^{\mathrm{b}}(1.36)$ & $3.72(1.15)$ & $\mathbf{4 . 0 0}^{\mathrm{ab}}(1.53)$ \\
\hline
\end{tabular}

Note: Means of emotional experiences on a scale from 1 (not at all) to 7 (extremely). Bold emotion scales match the prompt. Superscripts indicate significant differences at $p<.05$. The means reported for Study $2 \mathrm{~A}$ include the Belgian student sample only. Within each study, there were no cultural differences except for the negative disengaged situation in Study1: Korean ratings of negative disengaged emotions were higher than ratings for all other types of emotions. This was not the case for European Americans. 
Running head: EMOTIONAL ACCULTURATION

Table 2 Hierarchical Multiple Regression Analyses Predicting Immigrants' Emotional Concordance with the Average Mainstream Emotional Pattern

\begin{tabular}{|c|c|c|c|c|c|c|c|c|}
\hline \multicolumn{4}{|c|}{$\begin{array}{c}\text { Panel A: } \\
\text { Korean immigrants in the US }\end{array}$} & \multicolumn{5}{|c|}{$\begin{array}{c}\text { Panel B: } \\
\text { Turkish immigrants in Belgium }\end{array}$} \\
\hline Predictor & STUDY 1 & & & Predictor & STUD & Y 2 & STL & DY $2 A$ \\
\hline & Analysis 1 & $\Delta \mathbf{R}^{2}$ & $\beta^{\mathrm{a}}$ & Analysis 1 & $\Delta \mathbf{R}^{2}$ & $\beta^{\mathrm{a}}$ & $\Delta \mathbf{R}^{2}$ & $\beta^{\mathrm{a}}$ \\
\hline Step 1 & & $.528^{* * * *}$ & & Step 1 & $.521^{* * * *}$ & & $.574 * * *$ & \\
\hline Step 2 & $\begin{array}{l}\text { Valence } \\
\text { Engagement }\end{array}$ & .001 & $\begin{array}{l}-.642 * * * \\
-.081\end{array}$ & Valence & .001 & $-.729 * * *$ & .001 & $-.762 * * *$ \\
\hline & Educational att. & & .105 & Educational att. & & .060 & & .048 \\
\hline Step 3 & Proportion life in US & $.135^{* * *}$ & $.400 * * *$ & $\begin{array}{l}\text { Step } 3 \\
\quad \text { Proportion life in Belgium }\end{array}$ & $.017^{*}$ & $.135^{*}$ & $.012 *$ & $.112 *$ \\
\hline Total $R^{2}$ & & $.668 * * *$ & & Total $R^{2}$ & $.543 * * *$ & & $.587 * * *$ & \\
\hline & Analysis 2 & & & Analysis 2 & & & & \\
\hline Step 1 & & $.528 * * *$ & & Step 1 & $.521 * * *$ & & $.574 * * *$ & \\
\hline Step 2 & $\begin{array}{l}\text { Valence } \\
\text { Engagement }\end{array}$ & .001 & $\begin{array}{l}-.618^{* * *} \\
-.051\end{array}$ & Valence & .001 & $-.742 * * *$ & .001 & $-.757 * * *$ \\
\hline & Educational att. & & .069 & Educational att. & & .048 & & .039 \\
\hline Step 3 & Age & .000 & $-.247 \dagger$ & Step 3 & .006 & -.085 & .003 & -.110 \\
\hline Step 4 & Number of years US & $.073 *$ & $.399^{*}$ & $\begin{array}{l}\text { Step } 4 \\
\quad \text { Number of years Belgium }\end{array}$ & $.026^{* *}$ & $.229 * *$ & $.028^{* *}$ & $.238^{* *}$ \\
\hline Total $R^{2}$ & & $.636^{* * *}$ & & Total $R^{2}$ & $.562^{* * *}$ & & $.609^{* * *}$ & \\
\hline Analysis 3 & & & & Analysis 3 & & & & \\
\hline Step 1 & & $.528 * * *$ & & Step 1 & $.500 * * *$ & & $.557 * * *$ & \\
\hline Step 2 & $\begin{array}{l}\text { Valence } \\
\text { Engagement }\end{array}$ & .001 & $\begin{array}{l}-.647 * * * \\
-.046\end{array}$ & Valence & .002 & $-.708^{* * *}$ & .001 & $-.747 * * *$ \\
\hline Step 3 & Educational att. & $121 * * *$ & .105 & Educational att. & $.014 *$ & .063 & .008 & .066 \\
\hline & Age of Immigration & & $-.385 * * *$ & Age of Immigration & & $-.122 *$ & & -.089 \\
\hline Total $R^{2}$ & & $.661 * * *$ & & Total $R^{2}$ & $.522 * * *$ & & $.572 * * *$ & \\
\hline & Analysis 4 & & & Analysis 4 & & & & \\
\hline Step 1 & & $.528 * * *$ & & Step 1 & $.503 * * *$ & & $.565 * * *$ & \\
\hline & $\begin{array}{l}\text { Valence } \\
\text { Engagement }\end{array}$ & & $\begin{array}{l}-.626 * * * \\
-.075\end{array}$ & Valence & & $-.723 * * *$ & & $-.763 * *$ \\
\hline Step 2 & Educational att. & .001 & .018 & Educational att. & .002 & .066 & .001 & .045 \\
\hline Step 3 & Social Contact & $.057 *$ & $.258^{*}$ & Social contact & .000 & -.112 & .003 & -.069 \\
\hline & & & & $\begin{array}{l}\text { Step } 4 \\
\quad \text { Valence X Social Contact }\end{array}$ & $.015^{*}$ & $.160^{*}$ & $.016^{*}$ & $.173^{*}$ \\
\hline Total $R^{2}$ & & $.606^{* * * *}$ & & Total $R^{2}$ & $.519^{* * *}$ & & $.585 * * *$ & \\
\hline
\end{tabular}


Running head: EMOTIONAL ACCULTURATION

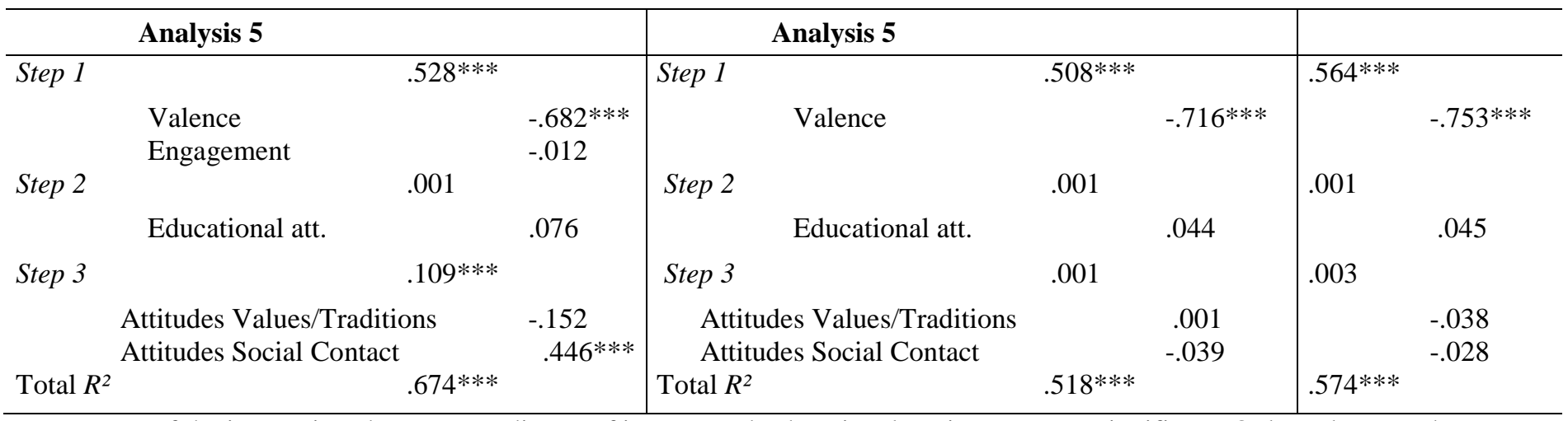

Note. None of the interactions between predictors of interest and Educational attainment were significant. Only Valence and

Social Contact interacted significantly in the Turkish sample in Belgium. For these reasons, we do not report these non-significant results of the fourth step in the analyses.

Analysis 1: predictor of interest is the proportion of life spent in the host culture; Analysis 2: predictor of interest is the number of years spent in the host culture, after controlling for age; Analysis 3: predictor of interest is the age of immigration; Analysis 4: predictor of interest is the amount of social contact with members of the host group; Analysis 5: predictors of interest are the direct measures of acculturation, namely attitudes towards the adoption of values and traditions and attitudes towards social contact with members of the host-group.

${ }^{a}$ The $\beta$ 's presented here are the ones from the final regression model, i.e. the latest step that significantly contributed to the explained variance.

$* \mathrm{p}<.05, * * \mathrm{p}<.01, * * * \mathrm{p}<.001$ 


\section{Notes}

${ }^{1}$ Psychological acculturation consists of two dimensions, one reflecting the degree to which a person has adopted mainstream culture, and the other referring to the maintenance of the heritage culture (e.g. Ryder, Alden \& Paulhus, 2000). Since we did not include samples of the cultures of heritage, our data offer a comparison of the immigrants to the host culture only, and thus shed light on their adoption of the host culture's emotional pattern, but not on their maintenance of the heritage culture's emotional pattern.

${ }^{2}$ We included explicit measures of cultural maintenance as well, despite the fact that we had no predictions with respect to the ways in which cultural maintenance of preferences, attitudes, etc. would relate to the adoption of mainstream patterns of emotion. In fact, the results did not show any systematic correlations, which led us to drop the discussion of these measures from the paper.

${ }^{3}$ With the 20-item emotional concordance variable as independent variable in the regression analysis, age of immigration failed to reach significance as a predictor of emotional concordance - although the effect was in the expected direction.

${ }^{4}$ The only exception to this was the experience of shame for Korean immigrants in the United States: The more Korean immigrants are engaged in North-American culture, the lower their reported levels of shame. This correlation occurred for all measures of acculturation, except for adoption of mainstream values and traditions. 